\title{
Educational Functions of Augmented Reality
}

\author{
Tomáš Jeřábek, Vladimír Rambousek
}

\begin{abstract}
The theoretical study presented in this paper focuses on the use of augmented reality systems in education. It analyses the specific characteristics of augmented reality and, in the context of these parameters, it formulates didactic specifics of augmented reality given by the complex of didactically relevant parameters of the didactic means that distinguish it from other devices in terms of supporting the accomplishment of educational intentions. The paper also defines educational intentions of using augmented reality for increasing the informational value, exposition of temporally and spatially disparate processes and phenomena, simulations of phenomena, events and processes, acquisition and building of competence in specific situations and instructing in activities. Following the educational intentions, the paper also proposes complex organisational criteria for the use of augmented reality applications, which include, in particular, the proposed location for the implementation of augmented reality, the number of students for whom augmented reality is intended, the anticipated role of a student in augmented reality, required mobility and required parameters of content presentation.
\end{abstract}

Keywords: augmented reality systems, educational function, didactic specifics, application, learning.

\section{INTRODUCTION}

The concept of augmented reality has been under development for many years and many systems of augmented reality, which were only laboratory experiments, have been put into common use in many areas of life. Augmented Reality is starting to break through as an innovative didactic tool that can help streamline and improve educational activities and become a suitable instrument for the promotion of cognitive processes in different educational areas (Cabero \& Barroso, 2016).

Augmented reality (AR) can be generally characterised as a specific innovative technology or technologically-induced perceptual environment based on a combination of a real environment with computergenerated information or virtual objects respectively. This creates a new form of the original reality that is richer in information than the original primary environment. The concept of AR was defined in this context as "overlapping of basic visual field with computer-generated data" (Heim, 1998), or as the addition of computer-generated contextual information layer into the real world, thus creating enriched, or augmented reality (Johnson et al., 2016). Augmented reality systems therefore (a) combine real environment surrounding the user with vir- 
tual elements, (b) are characterised by reactivity on the real environment in real time, (c) when registering virtual elements into perceived augmented reality, they count on three-dimensional space of the real environment (Azuma, 1997). The principle of augmented reality can be implemented in several ways using various technical devices and can work by its nature for all perceptual channels simultaneously or separately.

Besides the term, 'augmented reality', there are other labels and related terms in the literature, such as 'enhanced reality', 'mediated reality' or 'mixed reality'. For example, Milgram's concept of a virtual continuum defines an area of augmented reality and virtual reality within the mixed reality (Milgram, 1994). Terminology and mutual definition of these terms significantly diversify depending on the authors and on the field and the context in which they are mentioned. It could be noticed in the recent years that the term, 'mixed reality', begins to dominate as an umbrella term in the given field.

Augmented reality is realised by the help of various technical solutions (AR systems), each characterised by different properties, which significantly affect their possible use in education. AR systems can be divided into three basic categories (Jeřábek, Rambousek, \&Wildová, 2015): (1) systems with a HMD solution (Head-Mounted Display) [Azuma, 1997; Milgram, 1994; Rolland \& Hua, 2005; Prokýšek, Rambousek, \& Wildová, 2013), (2) handheld systems, and (3) stationary systems (Dunleavy, Dede, \& Mitchell, 2009; Drascic \& Milgram, 1996; Bimber
\& Raskar, 2005; Hong et al., 2014). The main criterion for the distribution of AR systems is the user mobility, which is essential for educational use.

Handheld or mobile systems (tablets, smartphones) currently represent the dominant group of AR systems, which enables both vision-based form of AR application form and also location-based (Dunleavy et al., 2009). It is thanks to their ever-increasing performance and also to the equipment of necessary input/output devices (camera, touch screen, GPS, location and position sensors, etc.). The main advantages of handheld systems are their affordability, mobility and their ability to work with multimedia content in terms of its acquisition and presentation. The systems enable virtually unlimited mobility of the user relative to augmented reality and usually do not require connectivity to an external computer for data processing as HMD systems do. To ensure continuous perception of augmented reality, the user is forced to provide a permanent device position in his field of view.

\section{Parameters of Augmented \\ Reality in the ConteXt \\ of EduCATION}

When examining the parameters of augmented reality that are of importance to education, it is necessary to base all facts on an assumption that AR is not merely a technical means, but the overall, technological-perceptual concept, which consists of an AR system and an AR environ- 


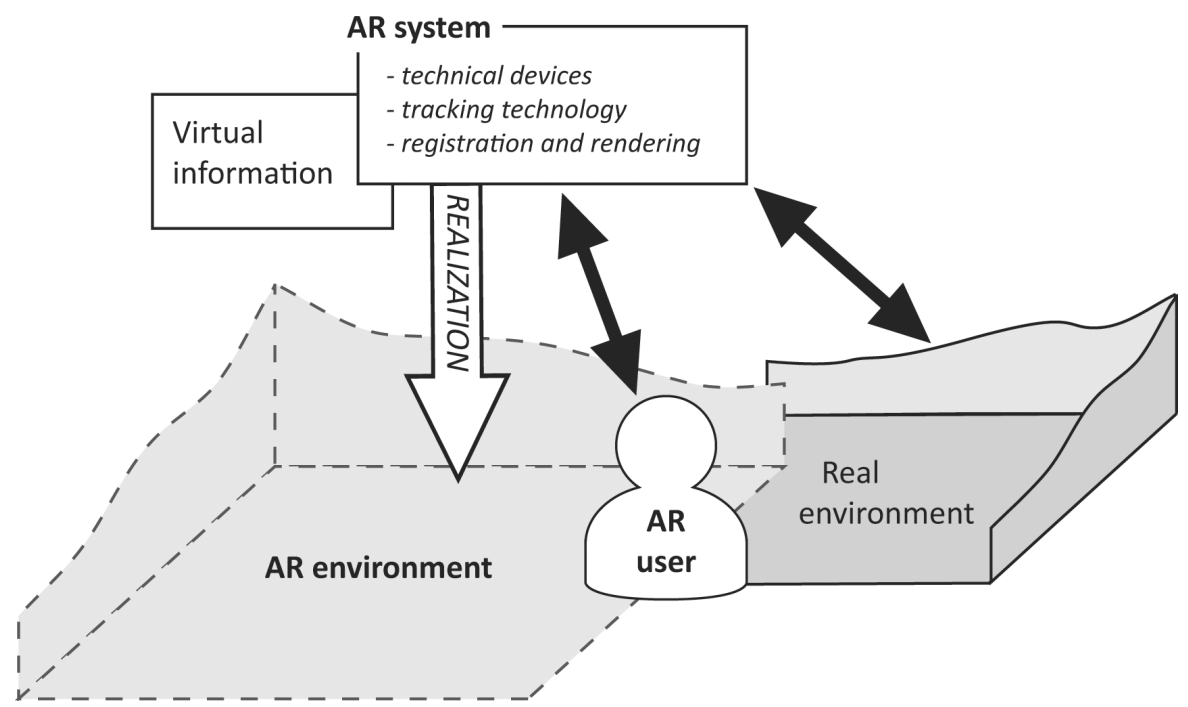

Fig. 1 Elements of technological-perceptual concept and their interactions

ment in which the student finds himself, or which influences him respectively. This technological-perceptual concept therefore comprises (a) technological, (b) perceptu$\mathrm{al}$, and (c) resultant aspects that reflect the technological aspects of AR systems, perceptual characteristics of the student and the properties of the resulting augmented reality environment, as indicated in Figure 1 (Jeřábek, Prokýšek, \& Rambousek, 2013). Technological aspects of AR systems largely predetermine the possibility of their use, including significance and possibility of their use in education.

The perceptual viewpoint can primarily assess the ability of the system to operate with different perceptual channels. It is to generate information, such as visual, auditory, tactile, and olfactory respectively. Determining the structure of perceptual aspects and identifying differences in the operation of AR are based on the functional principle of human sensory organs. In this context, there are things which are extremely important: (1) the localisation and the manner of the stimulus, and (2) the type of energy acting on the receptors. Augmented reality (as opposed to virtual reality) requires that all perceptions of generated virtual elements are in the context of the environment and are correctly localised in the real environment.

The resultant viewpoint of AR primarily reflects the properties of the environment and the relationship between virtual and real components from the user's perspective. 
These are the attributes characterising the desired output of AR application or system regardless of the technical design or perceptual areas with which the system operates.

\section{Didactic Specifics of Augmented Reality}

The concept of didactic specifics of augmented reality is based on the assumption that augmented reality can be understood as an innovative didactic tool, which can contribute to the enrichment of teaching resources and their functions, and become a suitable instrument for the promotion of educational activities. The assumption of didactic potential is based on the properties of augmented reality, which can take various forms by linking real environment with additional information, or increase the perceived value of information and the mediated content, and also provide different levels of mediality and modality in the transmission of information by different perceptual channels with the use of appropriate forms of sentient interaction with the content.

When examining the aspects, from which are derived the didactic specifics of augmented reality, it is necessary to rely on the fact that it is not just a mere technical means, but the overall technological and perceptual concept, which is formed partly by the AR system, and secondly by the AR environment, in which the student finds himself and which acts on him. At the same time there is a significant influence of the intention for the applications of augmented reality to be an educational resource.
The basic function and the fundamental peculiarity of augmented reality in the most general understanding, is the ability to connect reality with virtual elements and present these elements within the real environment. In terms of applicationfunction it is the ability of the technical means of augmented reality to real-time access to the addressee the reality deliberately enhanced with information that can take the nature of interpretation, management, content expansion, immersion and stimulation in order to achieve its educational goals. It is mainly the resulting viewpoint that will significantly determine the possible didactic use of augmented reality besides the nature of the added information, respectively the nature of augmented reality in terms of the relationship between the added information and the real environment.

The main didactic specifics of augmented reality can also be seen in the way of the mediation of sensations of perceived augmented reality, which would be very difficult to achieve using other technical means. This sensation, or the perceived virtual component respectively, is enhanced by its close co-existence with the surrounding real environment. This function to convey the sensation intensifies with the increasing immersion of the environment, which may be influenced by self-mediated content, type of device and quality of its presentation to users. In this context, augmented reality uses features and functions partially close to the virtual reality (Liou et al., 2017; Martín-Gutiérrez et al., 2017), especially in relation to the 
immersion, interactivity, simulation and scenarios, and is also based on the specifics of the environment in which augmented reality works.

Didactic specifics of augmented reality are largely derived from the technological and functional properties of AR systems. It is obvious that the properties and parameters of the systems largely determine the quality of mediated content, comfort of students working with augmented reality and limits of use within a variety of educational situations.

\section{Technological Viewpoint}

The parameter configuration of real and virtual component of $A R$ (T1) can play a significant role in terms of the selection of equipment and implementation of the educational plan.

Systems where the real component is directly perceived (especially optical HMD systems), are, by contrast, presumed to allow higher immersion, as is understood in the context of virtual reality since the perceptual field is not technically limited and the perception of the real component is almost natural.

The nature of control information (T2) significantly determines the possible didactic use of augmented reality systems, especially at the organisational and realisation level. Working with parameters of the real environment (e.g. image recognition) or parameters of the user (e.g., the user's location), augmented reality does not burden the conditions of its operation with the need for additional technical resources or specific artefacts. By contrast, the advantages of using a parameter in the form of a deliberately-placed component (e.g. $\mathrm{QR}$ code or a specific graphic element) lies in the ability to choose for the control parameter a didactically appropriate element, which is well suited due to the learning content of augmented reality, the conditions of the teaching situation and the intended target. Thus, it becomes not only a control parameter but also a teaching aid.

The case of recognition of control information in the surrounding reality entails requirements particularly for the lighting conditions in the environment in which there is augmented reality, or for the rate of reading of the environment. A determining technical parameter influencing these requirements is the quality of the imaging device in terms of light sensitivity, image resolution and frame rate.

The case of using user parameters as control information assumes tracking of geophysical position (e.g. using GPS technology) and the user's position, or the position of the device respectively. Technical constraints of the GPS limit the use of the augmented reality to environments with relatively open outdoor space and there is to be expected a deviation of up to several metres in determining the position of the system within the three-dimensional space of the primary environment. The advantage of this principle, however, is the independence of light conditions.

Parameter number of users (T3) who may simultaneously use one particular AR system and perceive through it a generated augmented reality is an important didactic 
specifics of particular systems, especially in terms of choice of suitable forms of application of the system to education.

Multi-user systems (especially stationary systems) are particularly suitable for collaborative, group or frontal forms of teaching. They allow students to change their position in relation to the system (e.g. free movement around the classroom), without reducing the effect of augmented reality or changing its content, and emphasise the shared augmented reality sensation among users.

Single-user systems offer a higher degree of personalisation in terms of setting a specific device according to the physiological differences between individual users and individualising student access to content through the device. Limited multi-user systems (especially handheld systems) are intended mainly for work in pairs or small groups.

The parameter support of interaction between user and system (T4) is a particularly important aspect in terms of the efficiency of application of augmented reality in education. Interactivity can be characterised by many aspects (Yacci, 2000; Moore, 1989). Besides the interaction between the student and the AR system (computer-based interaction - CBI; Lévy, 2000), there may also be considered the interaction between the student and content, or augmented reality environment respectively. Interaction here can be fulfilled on two levels, both by direct reaction of a real environment at the initiative of the student, and the system's response to this initiative in the form of providing feedback to the student. As a re- sult, it is possible to record three types of interaction within augmented reality in terms of participants: (a) student $\leftrightarrow$ real environment, (b) student $\leftrightarrow$ AR system, (c) student $\rightarrow$ real environment $\rightarrow$ AR system $\rightarrow$ student.

In all cases, the interaction of the participants can acquire various degrees and forms of interactivity, and its individual types can be mutually supportive and coherent. When looking at interactivity between the student and the system (either directly or through a real environment) we can express, from the system's perspective, different degree or level of interactivity. Variables that generally reflect the level of interactivity can be the frequency of reactions of the student to system events, and also the importance of the follow-up response of the system in order to influence the outcome or content, and scope which characterises the number of options that the student has available (Laurel, 1993).

In assessing the significance of interactivity of augmented reality, it is recommended to base assessment partly on the definition of the specifics in the context of virtual reality technology where interactivity requires dynamic simulation, because this is not only about the ability to navigate in the virtual world but also about the ability of users to change this environment (Ryan, 1994).

Considering an interaction as an intervention to the original real environment, it is possible to conclude about augmented reality that in all cases where the use of a real environment or deliberately-inserted artefact as control information with the possibility to manipulate this element, it 
fulfils interactivity at least at a so-called instrumental (first) Lister's degree of interactivity (Lister et al., 2009). At this degree Lister sees interaction as "the ability of user to directly intervene in the presented content and affect its appearance", while the variability in the amount of elements, the possibility to manipulate and combine can determine the degree of interactivity.

Within interactivity caused by the interaction between the student and the AR system there is no change in the primary real environment. A method of receiving instructions from the student, respectively the way of operating the system by the student, has a significant impact on comfort and clarity when using augmented reality.

Another possibility of affecting the system by the student is a contactless (optical, acoustic etc.) method by using certain commands, e.g., gestures and verbal commands or other determinable changes that the system is able to recognise.

\section{Perceptual Viewpoint}

The different character of graphical information, respectively the type of graphic data of virtual component (P1) is didactically very important. Together with the colour tone of the virtual components (depending on $\mathrm{P} 4$ ), we can characterise two basic conditions for the use of AR: (a) the pursuit of credibility of fusion of real and virtual component as one unit and (b) deliberate visual differentiation between the two components.

In the first case (a) it will be in didactic situations, which are to achieve immersion of students and credibility of AR. It can be, for example, a case of historical tours and displaying hidden parts of the real environment. In such cases, there will be the pursuit of a realistic and full-colour display, which will endeavour to reflect the light conditions of the real environment. Maximum fulfilment of this aim is still technically problematic and is related not only to the aforementioned perceptual aspects but also to the quality and character of presenting the content of AR. It is influenced by many technical aspects of AR systems. Problems related to the error rate of systems have been discussed in many technically-oriented works focused on augmented reality (Milgram, 1994; Dunleavy et al., 2009; Drascic \& Milgram, 1996) and include, for example, the problem of registration (inaccurate rendering of virtual components in terms of co-ordinates of the real environment), time delay (late presentation of one or both of the components inside the AR device) and the issue of collision of virtual objects with the real environment (Bren et al., 1996).

In the second case (b) when it is appropriate to visually distinguish between the virtual and the real component, we can characterise a function of the virtual component as description or instruction. It is therefore a situation where the virtual information is descriptive and is an addition to the real environment, but the resulting AR does not seek to "fool" the student by modification of the original environment to a new form of reality. In such situations, a virtual component is usually in the form of text, symbol or graphical information 
(or even audio instruction), while the emphasis must be on maximum readability of the original environment without visual modification so that a virtual component attracted students' attention sufficiently not to undermine the perception of the original environment.

\section{Resultant Viewpoint}

From the resultant viewpoint, the parameter ratio of real and virtual component of $A R(\mathrm{R} 1)$ is a particularly important didactic specific. It is mainly the specifics of (a) modified augmented reality, (b) enhanced augmented reality and (c) enriched augmented reality. Through appropriate choice of the specifics of this ratio, a student could find himself in an environment that is deliberately designed to provide favourable conditions for the fulfilment of an educational plan. It significantly increases the variability of didactic possibilities of the resulting environment and applied methods within which augmented reality can be used. The issue is the different content significance of the resulting $\mathrm{AR}$ and its emotional impact on students compared to the original environment or separately presented virtual information.

Within modified augmented reality, which is characterised by the removal of certain information from the user's perceptual field, it is possible to reduce the emotional effect of surrounding environment (e.g., to gradually accustom students to the environment) and it is also possible to assume some reduction in information density. In terms of usability in the context of didactic situations it is an important form of augmented reality, which should be considered particularly in the context of cognitive load (extraneous and intrinsic cognitive load) of the resulting environment from the primary one.

With enhanced augmented reality there can be assumed an increase in the content information from the original environment, while the virtual component is significantly associated with the primary environment. It is possible in this case to emphasise the particular demonstration of real elements, which are by their nature perceptually inaccessible to students. By adding an appropriate virtual element, phenomenon or process in a real context, according to the principle of visual correctness, exposition of and interest in the curriculum may be achieved.

Both the aforementioned forms of AR are based on an effort to keep as much of the essence of the original with a goal of modifying it considerably or only a little.

Didactic specifics of enriched reality consist mainly of mediation of virtual content, which is due, for example, to the historical, geographical, physical or security reasons not possible, appropriate or economical to implement without the use of augmented reality. The primary environment (real component) may be in terms of the proportion of AR components almost completely suppressed in order to enhance the student experience of the perception of added information.

In terms of the educational use of augmented reality, we can find a variety of educational functions based on the afore- 
mentioned parameters and didactic specifics. Such functions predispose augmented reality to its use as a didactic resource. Such didactic resource may assist in the realisation of a number of educational projects.

We used various theoretical research methods to determine didactic specifics, educational functions and organisational criteria of augmented reality. We used the inductive-deductive methods to determine didactic specifics. Then we applied terminological and content analysis of the phenomena of augmented reality and its didactic specifics, classification and relational analysis, examining AR systems from the informational and technological viewpoint in context of education. All analyses were based on the study of primary and secondary sources, their interpretation and comparison.

\section{Functions of Augmented Reality in Education}

Adapting the degree of emotional effects of a resulting environment of augmented reality and the correction of cognitive load can be considered the main educational functions common to all didactic situations using augmented reality. These features predetermine the use of augmented reality in education in many different forms and in different ways, which are possible to summarise as the following five main educational intentions with regard to the above didactic specifics:

1. increase the informational value

2. exposition of temporally- and spatiallydisparate processes and phenomena
3. simulations of phenomena, events and processes

4. acquisition and building of competence in specific situations

5. instructing in activities

For the purpose of increasing the information value, we can consider such applications of augmented reality in which the student is conveyed additional information on the real environment in order to increase the information value of the perceived environment. From the viewpoint of the phases of the educational process, these forms of augmented reality will find their use especially in the phase of exposure and fixation. Didactic environments within this group exhibit improved information density and by its nature this augmented reality falls into the category of enhanced AR.

Exposure of temporally-disparate processes and phenomena is characterised by the presented content, where a virtual component lies out of the current period in terms of the timeline. Emphasis is placed on the high level of immersion in the environment and the student's awareness of the historical context of a given location. These forms of augmented reality find their place in a broader array of methods, e.g., in the context of motivational methods, exposure, methods of problematic interpretation or heuristic methods. Interesting opportunities are offered by the exhibition of space-disparate phenomena, when we can insert into reality other virtual reality elements (buildings, plants, animals) from other locations for the purpose of motivation, assessment of the reality or comparing virtual and real objects. 
Simulation of phenomena, events and processes is characterised by an emphasis on highlighting virtual components representing a complex phenomenon or process, which could in many cases be used alone, without contextualisation with the real environment. By its use in the context of augmented reality, a student is able to better perceive and assess the issues presented by the curriculum and also to learn about new context of the phenomenon in the context of the primary environment. It is obvious that in terms of the type of knowledge and a way of acquiring knowledge is all about the methods of motivation and exposure.

Acquisition and building of competence in specific situations, like managing activities, is useful especially in the context of methods oriented on creating and developing skills and practical activities. In the context of previous studies, especially the experiments in medicine and military, it is possible to find several attempts for applying augmented reality in a form which is characterised by one of the two educational plans (Milgram, 1994; Brown, Coyne, \& Stripling, 2006; Hughes et al., 2005).

When acquiring and building competence in specific situations, augmented reality offers an environment with selected situations, which for safety reasons, complexity, inaccessibility, uniqueness or other organisational problems, are difficult, if not impossible to implement in the current real environment. The intent of such applications is to involve the student in the created situation to deal with a problem or look for the solution that may lie in the specific skills that may have characteristics of sensorimotor, mental or social.

Instructing in activities within augmented reality is related primarily to human activities that have a logical progression in time with defined individual successive steps. The instructing principle in AR involves entering guiding instructions in a realistic environment to streamline procedures within specific activities in light of time and quality, or eliminating possible errors. For this purpose we can use relatively simple instructions, such as numbers, signs or indicators, or audio instruction. The emphasis must be on maximum readability (maintaining the appearance) of the original environment. The given instructions must also be distinct from the surrounding environment (very low degree of realism) so that they attract students' attention, but they should not disturb concentration on the work to be performed. Within this category of augmented reality applications, the real component dominates in the real/virtual component ratio and it is most frequently enriched AR.

The aforementioned educational intentions can be identified in any educational situation. The case study of the applications of augmented reality in school practice at lower-secondary school (Jeřábek et al., 2013) can be taken as an example of this. We can also identify the didactic specifics of these applications from technological, perceptual and resultant view.

The educational intentions increase the information value can be identified, for instance, in the application, 'The History 
of Prague Castle'. This case of deployment required an easy mobility and enabled students to work in pairs. Control information are user parameters, namely, the location of the user and the position and orientation of the device. Students held the role of observers of augmented reality without participation. Application was characterised by a high degree of interactivity of the type student $\leftrightarrow$ AR system, with the mediation of various kinds of information in terms of quality and character. Through the device, the students were looking at the surrounding reality as a whole, to which were added textual and photographic information about objects lying in a certain direction and distance from the user.

Exposition of spatially-and temporallydisparate processes and phenomena can be identified in applications, 'Village' and 'Helmets'. The application, 'Village' was implemented in an outdoor environment, where students worked in pairs or small groups. As a control information was used specially-created graphic elements, which were entered into the surrounding terrain. The application principle lay in gradually adding the reference elements into the field of view and subsequent rendering of the virtual components in dependence on the used reference elements. This kind of application fills the third type of interaction - student $\rightarrow$ real environment $\rightarrow$ AR system $\rightarrow$ student. Control information for the system in the application, 'Helmets', was an element of real environment, specifically the face of the user. Application solution for the system was characterised by the active participation of users and relatively realistic virtual display components in the form of static or animated 2.5D objects (Prokýšek et al., 2013; Oh et al., 2011). The principle of the application was to display a virtual object in the form of historical helmets and pieces of armour from the shoulders up on the student. Interactivity within this application is a student $\leftrightarrow$ system, where the student has the option by touching the virtual element to obtain more information about the armour.

The applications, 'Bubonic Plague' and 'Moving Nations' represent the third category - simulation of phenomena, events and processes. From the perceptual and technological aspects the type of augmented reality solutions in 'Bubonic Plague' were the same as in the case of the application 'Helmets'. Students used answers to thematic issues to go through different stages of bubonic plague. Correct answers led to "cure". The application, 'Moving Nations', represents a visualisation of a phenomenon with the virtual component in the form of animation showing the changes in location of nations in Europe at specific times. A real component, respectively the reference element, is represented by a paper map and it was typically a singleuser solution independent of location. The method of control of application was similar to the application, 'Helmets', while enabling students to control augmented reality using graphical artefacts on the map. The application offered the interactivity type of student $\leftrightarrow$ AR system and also student $\rightarrow$ real environment $\rightarrow$ AR system $\rightarrow$ student. 
Acquisition and building of competence in specific situations can be identified in the creative application, 'Archimboldo'. It was about creating an image inspired by a particular style of the painter, Archimboldo, where students moved objects (virtual elements) on the screen represented by various fruits and drew up a collage depicting a face or a bust. Based on the nature of the added information it is a $2.5 \mathrm{D}$ static graphic, the image appears three-dimensional to the user and allows the system to compose in the $\mathrm{Z}$ axis. This application was filled with a high degree of interactivity type student $\leftrightarrow$ AR system.

\section{Organisational Criteria of AR Applications in Education}

For the desired effect of AR applications in education (Barroso Osuna \& Gallego Pérez, 2017), it is necessary to consider the complex of organisational aspects for the use of AR in addition to the specifications of the educational plan and the selection of AR system.

1. the proposed location for the implementation of augmented reality

2. the number of students for whom augmented reality is intended

3. the anticipated role of a student in augmented reality

4. required mobility

5. required parameters of content presentation

The location criterion should be considered as a priority. Firstly, it is necessary to consider whether it is important for the didactic situation to have a specifically de- fined location (e.g., classroom, building, sculpture etc.) or whether the object of augmentation are e.g., the students themselves, vehicles or other movable elements without ties to a specific location. In the first case, it also depends on whether it will be indoor activities, or outdoor activities, which can significantly limit the possibilities of using different control information (T2). It is also necessary to take into account organisational and technical support of the location, mainly due to the used systems (e.g., power supply, wifi access, space and light conditions, etc.).

The criterion of the number of students for whom augmented reality should be mediated, clearly compartmentalises each system and technological solution into categories corresponding to the technological aspect T3. When choosing a suitable technical solution, it must be based on the intended method and the organisational form of teaching with augmented reality. It is also necessary to consider whether the student interaction with the system affects affect also the sensation of other students. Multi-user systems compared to a singleuser seem more appropriate for group or collaborative learning. Even single-user systems with corresponding applications and interactions are, however, an appropriate solution for these forms of teaching with the benefit of the option to discuss the personalisation of the sensation (Kaufmann, 2004).

The criterion for the expected role of the student is the third of the monitored organisational criteria. According to the feeling of participation a student can either 
take a role of an observer, which is located outside of augmented reality, or be an active or passive user. While feeling to be in augmented reality, immersion significantly increases since the student is found inside augmented reality and its activity is more or less reflected into final AR. In terms of the relationship user-system-augmented reality, it is possible to distinguish between systems within the meaning of magic mirror and see-through (Zhen \& Blackwell, 2013) for systems providing the student with observation of the surrounding reality and its mirroring.

Systems that can provide mirroring of the surrounding reality, most often including the student himself (or even larger groups) and can be only from a group of handheld and stationary video systems. Augmented reality as a mirror offers a lot of room for applications with higher levels of interactivity of the student himself as an AR user. In such cases, there can be assumed a high degree of learning effectiveness and interest in the curriculum.

The criterion of mobility reflects primarily the student's mobility in the environment of augmented reality, which is allowed by the AR system while adapting presented augmented reality to the change of the student's position relative to the real environment. Systems that do not allow any mobility cannot be expected to be used for those forms of learning, which are based on exploring the surrounding environment and looking at it from various positions and perspectives.

Their use can be seen in the mediation of augmented reality based on an unchanging real environment or the ability to change the appearance of the real environment, e.g., through manipulation of the control information in the form of a reality parameter, or of an inserted artefact. Systems that do not limit students in terms of mobility, benefit from the possibility of changing the perspective of the augmented reality or its part, its active exploration and permit implementing a wide range of didactic intentions. Systems with a projection to the real environment allow relatively free movement in augmented reality without major restrictions thanks to their ability to present the content in the AR space without any display device.

Another viewpoint on mobility can be characterised as limiting the physical movement of the student by the system. Some systems require a clearly-defined location from where augmented reality can be perceived, and do not allow the student to change the location or position. Other solutions allow for virtually-unrestricted movement but limit the student by him having to hold the device in his hands (handheld systems). We can consider solutions with HMD to be the fully systems. Fully mobile systems are also such with the solutions of not requiring any physical contact with the device, and fully cover the area of student's perception relative to the size of the real environment.

The criterion of parameters of the content presentation includes requirements for image quality of augmented reality, accuracy in the registration stage, delay, respectively the collision of virtual objects with the real environment and other 
aspects related to the user's perception of AR (Drascic \& Milgram, 1996; Bimber \& Raskar, 2005; Oh et al., 2011).

Properties of the presented content from the perspective of computer graphics and generally any display can be in the context of the parameters of content presentation described as the image quality. Fulfilling the aspects of colour information, the nature of graphic data and dynamic character of images can be described in terms of the purely technical aspect as trouble-free for most of the currently available AR systems. Conversely, the image resolution for individual systems may vary considerably and the smaller devices can be particularly limiting.

When choosing a suitable solution in terms of registration in the context of the intended didactic situation, it is necessary to take into account how precise it must be to set the virtual element into reality, and also form the desired mobility. The problem of registration is closely linked with possible delays in rendering the information to the correct position in the real environment. Excessive delays reduce comfort when working with augmented reality, which can consequently cause demotivation of students to use augmented reality. While using AR applications, which require a very fast system response to the change of control information (e.g., training of fast model situations), any noticeable delay by the student is unacceptable.

An important parameter, that affects an augmented reality sensation of students, is the degradation of the perceptual field, which is caused by a technical de- sign, respectively the principle of the given system. To achieve the intention of the augmented reality applications, it is appropriate in most cases for the AR system to provide such a view of augmented reality, which most closely matches the normal perceptual field of the student, thus not undermining the complexity of the perception of augmented reality as a whole.

There are described the selected AR systems according to the aforementioned organisational criteria in the summary Table 1.

\section{Conclusion}

Problematics in using the technological and perceptual concept of augmented reality in education are complex and, besides its own technological viewpoint, it includes various other aspects of the investigation of augmented reality as an educational means, which is characterised by the complex of didactic specifics. Elaborating on this issue assumes examining these didactic specifics, defining educational functions and specification of organisational viewpoints of AR applications in education. When examining these areas it is necessary to consider all the technological, perceptual and resulting parameters of augmented reality, which reflect the relevant characteristics of each part of this concept and their interrelationships. The problematics of augmented reality in education also include the analysis of the didactic use of augmented reality in the context of each of the aforementioned parameters, the importance of which varies in terms of didactic use. 
Table 1 Fulfilment of the organisational criteria from the selected AR systems ( $\mathrm{y}$ - system fulfils criteria, $\mathrm{n}$ - system does not fulfil criteria, ? - impossible to decide)

\begin{tabular}{|c|c|c|c|c|c|c|c|c|c|}
\hline & 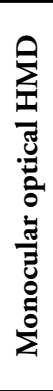 & 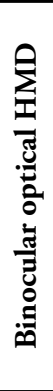 & 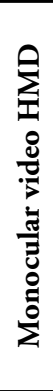 & 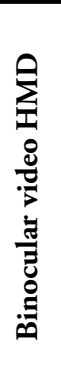 & 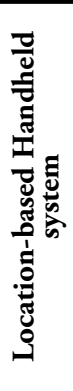 & 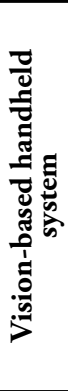 & 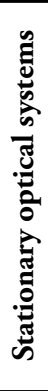 & 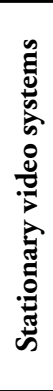 & 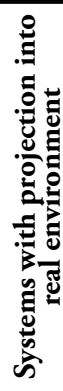 \\
\hline Indoors $(\mathrm{y}, \mathrm{n})$ & $\mathrm{y}$ & $\mathrm{y}$ & $\mathrm{y}$ & $\mathrm{y}$ & $?$ & $\mathrm{y}$ & $\mathrm{y}$ & $\mathrm{y}$ & $\mathrm{y}$ \\
\hline Outdoors $(\mathrm{y}, \mathrm{n})$ & $\mathrm{y}$ & $\mathrm{y}$ & $\mathrm{y}$ & $\mathrm{y}$ & $\mathrm{y}$ & $\mathrm{n}$ & $\mathrm{n}$ & $\mathrm{n}$ & $\mathrm{n}$ \\
\hline Requiring the change of position $(y, n)$ & $?$ & $?$ & $?$ & $?$ & $\mathrm{y}$ & $\mathrm{n}$ & $\mathrm{n}$ & $\mathrm{n}$ & $\mathrm{n}$ \\
\hline Location is not important $(\mathrm{y}, \mathrm{n})$ & $\mathrm{y}$ & $\mathrm{y}$ & $\mathrm{y}$ & $\mathrm{y}$ & $\mathrm{n}$ & $\mathrm{y}$ & $\mathrm{y}$ & $\mathrm{y}$ & $\mathrm{n}$ \\
\hline One $(y, n)$ & $\mathrm{y}$ & $\mathrm{y}$ & $\mathrm{y}$ & $\mathrm{y}$ & $\mathrm{y}$ & $\mathrm{y}$ & $\mathrm{y}$ & $\mathrm{y}$ & $\mathrm{y}$ \\
\hline Limited number $(y, n)$ & $\mathrm{n}$ & $\mathrm{n}$ & $\mathrm{n}$ & $\mathrm{n}$ & $\mathrm{y}$ & $\mathrm{y}$ & $\mathrm{y}$ & $\mathrm{y}$ & $\mathrm{y}$ \\
\hline Larger group $(\mathrm{y}, \mathrm{n})$ & $\mathrm{n}$ & $\mathrm{n}$ & $\mathrm{n}$ & $\mathrm{n}$ & $\mathrm{n}$ & $\mathrm{n}$ & $?$ & $\mathrm{y}$ & $\mathrm{y}$ \\
\hline Observer $(\mathrm{y}, \mathrm{n})$ & $\mathrm{y}$ & $\mathrm{y}$ & $\mathrm{y}$ & $\mathrm{y}$ & $\mathrm{y}$ & $\mathrm{y}$ & $\mathrm{y}$ & $\mathrm{y}$ & $\mathrm{y}$ \\
\hline Participant (mirroring) $(\mathrm{y}, \mathrm{n})$ & $\mathrm{n}$ & $\mathrm{n}$ & $\mathrm{n}$ & $\mathrm{n}$ & $\mathrm{y}$ & $\mathrm{y}$ & $\mathrm{n}$ & $\mathrm{y}$ & $\mathrm{n}$ \\
\hline $\begin{array}{l}\text { Reflecting the changes of the } \\
\text { student's position }(y, n)\end{array}$ & $\mathrm{y}$ & $\mathrm{y}$ & $\mathrm{y}$ & $\mathrm{y}$ & $\mathrm{y}$ & $\mathrm{y}$ & $?$ & ? & $\mathrm{n}$ \\
\hline Movement of student in AR $(y, n)$ & $\mathrm{y}$ & $\mathrm{y}$ & $\mathrm{y}$ & $\mathrm{y}$ & $\mathrm{y}$ & $\mathrm{y}$ & $\mathrm{n}$ & $?$ & $\mathrm{y}$ \\
\hline Limiting the movement of student $(y, n)$ & $y / ?$ & $\mathrm{y} / ?$ & $\mathrm{y} / ?$ & $y / ?$ & $\mathrm{n}$ & $\mathrm{n}$ & $?$ & $\mathrm{n}$ & $\mathrm{n}$ \\
\hline Image quality (low, high) & 1 & 1 & 1 & 1 & $\mathrm{~h}$ & $\mathrm{~h}$ & $?$ & $\mathrm{~h}$ & $\mathrm{~h}$ \\
\hline Spatiality $(y, n)$ & $\mathrm{n}$ & $\mathrm{y}$ & $\mathrm{n}$ & $\mathrm{y}$ & $\mathrm{n}$ & $\mathrm{n}$ & $?$ & $?$ & $\mathrm{y}$ \\
\hline $\begin{array}{l}\text { Elimination of degradation of } \\
\text { perception (no, low, medium, high) }\end{array}$ & 1 & $\mathrm{n}$ & $\mathrm{m}$ & $\mathrm{m}$ & $\mathrm{h}$ & $\mathrm{h}$ & 1 & $\mathrm{~m}$ & $\mathrm{n}$ \\
\hline
\end{tabular}

Exploring the educational potential of augmented reality in education involves identifying the educational functions of AR. In connection with this, we can define five basic educational intentions, which can be seen at integrating augmented reality into the education. These intentions are based on the fundamental and essential educational functions of AR, which are the correction of emotional effects of the environment on students and the correction of cognitive load. Educational intentions have in this context their own specifics and also different requirements for the choice 
of an AR system and for the complex of organisational conditions for learning. For suitable didactic use of augmented reality, in addition to the educational plan, it is necessary to consider also the organisational aspects for the educational use of AR. Five organisational criteria can be defined: the intended location for realisation of augmented reality, the number of students for whom augmented reality is designed, the anticipated role of students in augmented reality, the required mobility and the required parameters of augmented reality content presentation. These criteria must be taken into account in the context of the choice of the AR system and the educational intention.

Finally, it is necessary to emphasise that to achieve the desired educational effect of AR and to reach the educational potential of this medium, it is essential to consider the inclusion of AR in learning activities at three interrelated levels. The first level is the choice of the educational intention, which the teacher wants to achieve. Following the required intention, it is necessary to take into account the organisational criteria, owing to the nature of the educational intention and given the nature of the curriculum and options available within the intended educational environment. Taking into account these two levels, then it is possible to select the appropriate AR system that best suits the intended learning activity. However, the limiting factor is the equipment of AR systems. In all cases, the execution of the educational intention must be based on the available AR system, and there is a need to accordingly customise the concept of the educational intention, and the organisation of its implementation.

When considering further research work in this area, we suggest a focus on research to verify the effectiveness of the educational process using various AR systems for the specific educational intentions determined and with regarding the organisational criteria.

\section{REFERENCES}

Azuma, R. T. (1997). A survey of augmented reality. Teleoperators and Virtual Environments, 6. Barroso Osuna, J. M., \& Gallego Pérez, O. M. (2017). Producción de recursos de aprendizaje apoyados en Realidad Aumentada por parte de estudiantes de magisterio. Revista de Educación Mediática y TIC, 6(1), 23-38.

Bimber, O., \& Raskar, R. (2005). Spatial augmented reality: merging real and virtual worlds. A. K. Peters.

Breen, D. E., et al. (1996). Interactive Occlusion and Automatic Object Placement for Augmented Reality. Computer Graphics Forum (Proc. Eurographics '96), 15(3), 11-22.

Brown, D. G., Coyne, J. T., \& Stripling. R. (2006). Augmented reality for urban skills training. $V R$ '06: Proceedings of the IEEE conference on Virtual Reality (p. 249-252).

Cabero, J., \& Barroso, J. (2016). The educational possibilities of augmented reality. Journal of New Approaches in Educational Research, 5(1), 44-50. 
Drascic, D., \& Milgram, P. (1996). Perceptual issues in augmented reality. SPIE Volume 2653: Stereoscopic Displays and Virtual Reality Systems III.

Dunleavy, M., Dede, C., \& Mitchell, R. (2009). Affordances and limitations of immersive participatory augmented reality simulations for teaching and learning. Journal of Science Education and Technology, 18(1), 7-22.

Heim, M. (1998). Virtual realism. New York: Oxford University Press.

Hong, K., Yeom, J., Jang, C., Hong, J., \& Lee, B. (014). Full-color lens-array holographic optical element for three-dimensional optical see-through augmented reality. Optics Letters, 39, 127-130.

Hughes, C. E., Stapleton, C. B., Hughes, D. E., \& Smith, E. M. (2005). Mixed reality in education, entertainment, and training. IEEE Comput. Graph. Appl., 25, 24-30.

Jeřábek, T., Prokýšek, M., \& Rambousek, V. (2013). Parameters of augmented reality and its use in education. Journal on Efficiency and Responsibility in Education and Science, 6(4), 232-244.

Jeřábek, T., Rambousek, V., \& Wildová, R. (2015). Perceptual specifics and categorisation of augmented reality systems. Procedia - Social and Behavioral Sciences, 191, 1740-1744.

Johnson, L., Adams Becker, S., Cummins, M., Estrada, V., Freeman, A., \& Hall, C. (2016). $N M C$ horizon report: higher education edition. Austin, Texas: The New Media Consortium.

Kaufmann, H. (2004). Geometry education with augmented reality. Wien: Springer.

Laurel, B. (1993). Computers as theatre. Boston: Addison-Wesley Professional.

Lévy, P. (2000). Kyberkultura. Praha: Karolinum.

Liou, H.-H., Yang, S. J. H., Chen, S. Y., \& Tarng, W. (2017). The influences of the 2D imagebased augmented reality and virtual reality on student learning. Journal of Educational Technology and Society, 20(3), 110-121.

Lister, M., Dovey, J., Giddings, S., Grant, I., \& Kelly, K. (2009). New media: a critical introduction. 2nd ed. London: Routledge.

Martín-Gutiérrez, J., Mora, C. E., Anorbe-Díaz, B., \& Gonzáles-Marrero, A. (2017). Virtual technologies trends in education. EURASIA Journal of Mathematics Science and Technology Education, 13(2), 469-486.

Milgram, P. (1994). A taxonomy of mixed reality visual displays. IEICE Transactions on Information Systems, E77-D(12).

Moore, M. G. (1989). Three types of interaction. American Journal of Distance Education, 3(2).

Oh, K. E. et al. (2011). Which properties in 3D visualizations cause comprehension difficulties? Proceedings of the American Society for Information Science and Technology, 48(1), 1-4.

Prokýšek, M., Rambousek, V., \& Wildová, R. (2013). Research into spatial intelligence and the efficiency of the application of spatial visualization in instruction. Procedia - Social and Behavioral Sciences, 84, 855-859.

Rolland, J. P., \& Hua, H. (2005/2003). Head-mounted display systems. In R. Driggers (Ed.), Encyclopedia of Optical Engineering (p. 1-13). New York: Marcel Dekker. 
Ryan, M. L. (1994). Immersion vs. interactivity: virtual reality and literary theory [online]. Available from www.humanities.uci.edu

Yacci, M. (2000). Interactivity demystified: A structural definition for distance education and intelligent CBT. Educational Technology.

Zhen, B., \& Blackwell, A. F. (2013). See-through window vs. magic mirror: A comparison in supporting visual-motor tasks. Mixed and Augmented Reality (ISMAR). IEEE International Symposium (p. 239-240).

Tomás Jerábek (Czech Republic), Charles University, Faculty of Education;

e-mail: tomas.jerabek@pedf.cuni.cz

Vladimir Rambousek (Czech Republic), Charles University, Faculty of Education;

e-mail: vladimir.rambousek@pedf.cuni.cz 